\title{
O CONHECIMENTO DOS PAIS QUANTO AO PROCESSO DO CUIDAR POR MEIO DO BRINCAR
}

\author{
Aderlaine da Silva Sabino¹, Arinete Véras Fontes Esteves², Ana Paula Pessoa de Oliveira³ , Marcos \\ Vinícius Gusmão da Silva ${ }^{4}$.
}

RESUMO: Objetivo: verificar a percepção dos pais e/ou responsáveis legais de crianças hospitalizadas sobre a atividade do brincar como uma dimensão do cuidado de Enfermagem. Método: estudo qualitativo, descritivo, exploratório e prospectivo, baseado na análise categorial temática. Realizou-se entrevista semiestruturada em um Hospital Infantil de referência do Amazonas, no mês janeiro de 2016. Participaram 22 pais com idade entre 18 e 50 anos. Da análise, emergiram as categoriais temáticas "Significado da brincadeira e brincar", "Importância do brinquedo durante a prática do brincar para a criança hospitalizada" e "O cuidar brincando". Resultados: os pais reconheceram a importância do brincar durante o processo de cuidar em ambiente pediátrico, mas não visualizaram a atividade inserida no plano de cuidado dos profissionais de modo que a singularidade da criança seja respeitada em sua integralidade nesse sentido. Conclusão: há a necessidade de capacitar e sensibilizar os profissionais para utilizar o brincar em sua prática assistencial. DESCRITORES: Enfermagem; Família; Criança hospitalizada; Ludoterapia; Cuidado da criança.

\section{THE PARENTS' KNOWLEDGE ON THE CARE PROCESS THROUGH PLAY}

\begin{abstract}
Objective: verify how the parents and/or legal caregivers of hospitalized children perceive playing as a dimension of Nursing care. Method: qualitative, descriptive, exploratory and prospective study, using theme/category-based analysis. A semistructured interview was held at a Children's Hospital of reference in the State of Amazonas in January 2016. The participants were 22 parents between 18 and 50 years of age. The thematic categories "Meaning of play and playing", "Importance of the toy during playing practice for hospitalized children" and "Care while playing" emerged from the analysis. Results: the parents acknowledged the importance of playing during the care process in pediatric contexts, but did not envisage the activity as part of the professionals' care plan, so that the child's singularity can be fully respected in that sense. Conclusion: the professionals need qualification and awareness raising to use play in their care practice.
\end{abstract}

DESCRIPTORS: Nursing; Family; Child, hospitalized; Play Therapy; Child Care.

\section{EL CONOCIMIENTO DE LOS PADRES ACERCA DEL PROCESO DEL CUIDAR POR MEDIO DEL JUGAR}

RESUMEN: Objetivo: evaluar la percepción de los padres y/o responsables legales de niños hospitalizados acerca de la actividad del jugar como una dimensión del cuidado de Enfermería. Método: estudio cualitativo, descriptivo, exploratorio y prospectivo, basado en el análisis de categoría temática. Se realizó entrevista semi estructurada en un Hospital Infantil de referencia en Amazonas, en el mes de enero de 2016. Participaron 22 padres con edad entre 18 y 50 años. Del análisis, resultaron las categorías temáticas "Significado del juego y del jugar", "Importancia del juguete durante la práctica del jugar para el niño hospitalizado" y "El cuidar jugando". Resultados: los padres reconocieron la importancia del jugar durante el proceso de cuidar en ambiente pediátrico, pero no visualizaron la actividad presente en el plan de cuidado de los profesionales de modo que la singularidad del niño sea respetada en su integralidad en ese sentido. Conclusión: hay necesidad de capacitar y sensibilizar a los profesionales para utilizar el jugar en su práctica asistencial.

DESCRITORES: Enfermería; Familia; Niño hospitalizado; Ludoterapia; Cuidado del niño.

\footnotetext{
1Enfermeira. Mestre em Enfermagem. Professora da Universidade Luterana de Manaus. Manaus, AM, Brasil.

${ }^{2}$ Enfermeira. Doutora em Psicologia. Professora Associada da Universidade Federal do Amazonas. Manaus, AM, Brasil.

${ }^{3}$ Enfermeira. Doutora em Psicologia. Professora Adjunta da Universidade Federal do Sul da Bahia. Salvador, BA, Brasil.

${ }^{4}$ Acadêmico do Curso de Enfermagem da Universidade Federal do Amazonas. Amazonas, AM, Brasil.
} 


\section{INTRODUÇÃO}

Na infância, o adoecer e a hospitalização das crianças são fatores que desafiam o desenvolvimento saudável, pois a internação possibilita a manifestação de um amadurecimento precoce para esta fase. Nesse momento, faz-se necessário o ser infante habituar-se a mudanças na sua rotina buscando compreender suas possíveis limitações físicas impostas pela enfermidade e perceber que os obstáculos no decorrer do seu adoecer o tornarão mais forte emocionalmente ${ }^{(1-2)}$.

A internação provoca, também, sentimento de incerteza para os acompanhantes/familiares, que passam a interiorizar seus sentimentos, tentando disfarçar sua ansiedade e preocupação, ficam receosos de se ausentar do leito do infante, temendo o pior e deixando, nesse momento, de olhar para si enquanto pessoa que, também, tem necessidades para garantir o seu bem-estar e, consequentemente, o da criança ${ }^{(3)}$.

Segundo os familiares, a criança fica assustada no hospital e, para confirmar essa percepção, os profissionais da saúde relatam o medo observado frequentemente nas crianças relativo aos procedimentos realizados e aos sons dos equipamentos que são utilizados para tais procedimentos ${ }^{(4)}$.

Em decorrência dessas situações, a utilização do lúdico durante a assistência de Enfermagem é vista, pelos acompanhantes, como uma atividade benéfica que pode facilitar a aceitação da criança quanto à realização de procedimentos dolorosos como, por exemplo, a punção venosa, pois essas atividades contribuem para tornar o ambiente hospitalar mais agradável proporcionando distração e lazer ${ }^{(5)}$.

Portanto, para os acompanhantes, o brincar é uma atividade que oferece a possibilidade de a criança internada relaxar, de sentir-se segura em ambientes estranhos e com pessoas desconhecidas, diminuindo o desgaste familiar com a criança enferma, ao mesmo tempo em que abre espaço para a resolução de problemas pessoais pendentes por parte de seus acompanhantes ${ }^{(6)}$.

Assim, de acordo com a Lei Federal de no 11.104, datada de 21 de março de 2005, todos os hospitais que ofereçam atendimento pediátrico deverão conter, obrigatoriamente, brinquedotecas em suas dependências, oferecendo um espaço provido de brinquedos e jogos educativos destinados a estimular as crianças e seus acompanhantes a brincarem ${ }^{(7)}$.

Diante disso, a brinquedoteca é um espaço de lazer para a criança capaz de promover a criatividade, a espontaneidade e a afetividade respeitando as necessidades dela. Trata-se, portanto, de um espaço educacional essencial para o infante ${ }^{(8)}$.

Os familiares percebem que, a partir da interação de suas crianças com outros infantes, com a mesma condição de adoecimento, a criança passa a ter maior compreensão das limitações impostas pela doença possibilitando novos significados a diferentes brincadeiras vivenciadas no dia a dia ${ }^{(9-10)}$.

Ao considerar o papel do profissional de saúde no ambiente pediátrico, cabe ao mesmo concernir, em sua pluralidade, o cuidado à criança de modo que ela possa expressar suas percepções e necessidades peculiares $^{(11)}$.

Contudo, é necessário que o profissional de saúde entenda que a realização de práticas lúdicas com desenhos, leituras de gibis, jogos, palhaços, contar histórias e métodos audiovisuais faz parte do plano assistencial e que esteja inclusa durante os procedimentos e cuidados a fim de distrair, aliviar o medo, a insegurança e a dor física ${ }^{(12)}$.

Nesse contexto, mesmo diante da compreensão da importância do brincar para as crianças, muitas vezes, esse brincar lhes é negado, apesar de seus direitos serem instituídos por lei. Por isso, este estudo propõe verificar a percepção dos pais e/ou responsáveis legais sobre a atividade do brincar como uma dimensão do cuidado de Enfermagem à criança hospitalizada. 


\section{METODOLOGIA}

Trata-se de um estudo de abordagem qualitativa, de caráter descritivo, exploratório e prospectivo, pois objetiva o fenômeno que descreve, compreende e explica um universo de significados, motivos, aspirações, crenças, valores e atitudes que correspondem a um espaço mais profundo das diferentes relações, de processos e fenômenos ${ }^{(13)}$.

O estudo foi desenvolvido em uma unidade de atendimento à criança e ao adolescente, da rede estadual de saúde de Manaus/Amazonas, composto por uma equipe multidisciplinar e multiprofissional com especialidades em consultas ambulatoriais, cardiologia pediátrica e cirurgião pediatra.

A Clínica Cirúrgica, cenário da pesquisa, possui 22 leitos distribuídos em quatro enfermarias, sendo duas com seis leitos e duas com capacidade para cinco leitos. Os participantes selecionados para a pesquisa foram $100 \%$ dos pais acompanhantes considerando-se como critérios de inclusão: estar acompanhando a criança internada na unidade cirúrgica por mais de setenta e duas horas, nos meses da coleta dos dados, no período diurno (7h às $12 \mathrm{~h}$ ) e aceitar a condição de voluntário para responder à pesquisa. O critério de exclusão da amostra foi a desistência do participante por qualquer motivo.

Para manter o anonimato, os participantes estão identificados por pseudônimos correspondentes aos nomes das tribos indígenas do Estado do Amazonas: Apiaká, Apurinã, Atroari, Baniwa, Deni, Dessanas, Hixbaryana, Hupda, Jamamadi, Jarawara, Katukina, Kaxarari, Kaxinawá, Kulina, Marubo, Matis, Mayoruna, Muras, Mundurukus, Sateré-Mawé, Ticuna e Tucano.

O procedimento de coleta dos dados foi registrado por meio de entrevista semiestruturada ${ }^{(13)}$, gravada e transcrita para a análise, seguindo o roteiro das perguntas, com questões de múltipla escolha (sim, não e às vezes), seguidas do pedido de justificativa. As entrevistas foram realizadas durante os meses de dezembro de 2015 a janeiro de 2016, diariamente, de segunda a sexta-feira, no período matutino, das $07 \mathrm{~h}$ às $12 \mathrm{~h}$, individualmente, com os colaboradores da pesquisa.

Os participantes responderam às perguntas na própria enfermaria, ao lado do leito da criança, e cada entrevista teve duração média de 20 minutos. Para manter a fidedignidade das respostas, foi utilizado um gravador de áudio (MP3) a fim de obter as informações, por meio da fala individual, transmitindo as representações de cada colaborador do estudo que foram, posteriormente, transcritas na íntegra.

A pesquisa se norteou a partir das seguintes indagações: Os familiares ou responsáveis legais já tiveram alguma experiência em relação à atividade do brincar dentro de uma unidade hospitalar? Os profissionais de saúde que cuidam de infantes realizam a atividade do brincar durante a assistência? Quanto à utilização da atividade do brincar durante o atendimento à criança hospitalizada, o familiar compreende que esta pode influenciar na recuperação de seu filho? Quais os benefícios da atividade do brincar para a criança hospitalizada durante o tratamento? O cuidado associado à atividade do brincar auxilia a criança a compreender seu novo momento de vida, mesmo quando hospitalizada?

Importante ressaltar que todos os responsáveis aceitaram participar como colaboradores no estudo após as informações fornecidas aos mesmos esclarecendo o objetivo da pesquisa, a importância de sua participação e a disponibilidade em cooperar.

Os dados coletados foram analisados de acordo com o método de Análise de Conteúdo ${ }^{(13)}$ por meio da escuta atentiva das entrevistas e, posteriormente, sua transcrição, mantendo-se fiel às falas e estabelecendo, assim, a apreciação de cada etapa da pesquisa, segundo as orientações e procedimentos de Minayo ${ }^{(13)}$, que desenvolve técnicas de Análise Temática, na pesquisa qualitativa, subdivididas em três momentos: pré-análise (fase de organização e preparo do material); exploração do material (organização, agrupamentos e categorização), tratamento e interpretação dos resultados.

A metodologia utilizada permite ampliar a visão do pesquisador acerca do conteúdo estudado visto que facilita a compreensão das necessidades da saúde pediátrica pelos profissionais de Enfermagem e acompanhantes obtida a partir das visões, sentimentos e necessidades da criança, contidas na resolução COFEN 295/2004, fortalecendo, portanto, a assistência integral de qualidade realizada pela equipe de Enfermagem, que permanece prestando cuidados à criança e orientando os familiares durante grande parte da hospitalização da criança ${ }^{(14)}$. 
A proposta de pesquisa foi submetida ao Comitê de Ética em Pesquisa da Universidade Federal do Amazonas (CEP/UFAM) e aprovada com o parecer no 1.082 .405 .

\section{RESUlTADOS}

A pesquisa permitiu fazer um levantamento do perfil dos acompanhantes em relação ao sexo, grau de parentesco, faixa etária, naturalidade, escolaridade, profissão e tempo de internação e do Diagnóstico Clínico da criança, com os dados apresentados a seguir.

Dos 22 entrevistados, 21 (95,45\%) eram do sexo feminino. Quanto ao grau de parentesco, 19 $(83,36 \%)$ eram mães, havendo três $(13,64 \%)$ acompanhantes que foram identificados como tia, irmã e pai da criança.

A faixa etária dos acompanhantes foi entre 18 e 50 anos. Quanto à sua naturalidade, dez (45,45\%) acompanhantes eram do município de Manaus - AM. Dos restantes, dois (9,09\%) eram de ManaquiriAM e os demais oriundos de Anamã, Barreirinha, Coari, Eirunepé, Lábrea, Oriximinã, Parintins e Pauiní, que são municípios do Amazonas, de Santarém, no Estado do Pará, e de Serra Madureira, no Estado do Acre.

Quanto à escolaridade, seis $(27,27 \%)$ entrevistados tinham o ensino fundamental incompleto e quatro $(18,18 \%)$ haviam finalizado o nível superior. Destaca-se, também, que não foi evidenciado acompanhante analfabeto na pesquisa, de acordo com a tabela 1.

Tabela 1 - Escolaridade dos participantes do estudo. Manaus, AM, Brasil, 2016

\begin{tabular}{lcc}
\hline Escolaridade & $\mathbf{n}$ & $\mathbf{\%}$ \\
\hline Ensino fundamental incompleto & 6 & 27,27 \\
Ensino médio incompleto & 5 & 22,73 \\
Ensino superior completo & 4 & 18,18 \\
Ensino médio completo & 5 & 22,73 \\
Ensino superior incompleto & 1 & 4,55 \\
Ensino fundamental completo & 1 & 4,55 \\
\hline Total & $\mathbf{2 2}$ & $\cong \mathbf{1 0 0}$ \\
\hline
\end{tabular}

Segundo os dados referentes à profissão, predominou "do lar", representando nove sujeitos (40,91\%) do público-alvo, além das profissões de diarista, estudante e manicure, que apresentaram o segundo maior percentual, dois $(9,09 \%)$, conforme a tabela 2 .

Tabela 2 - Profissões dos acompanhantes. Manaus, AM, Brasil, 2016. (continua)

\begin{tabular}{lcc}
\hline Profissão & $\mathbf{n}$ & $\mathbf{\%}$ \\
\hline Do Lar & 9 & 40,91 \\
Agricultora & 1 & 4,55 \\
Estudante & 2 & 9,09 \\
Analista de RH & 1 & 4,55 \\
Professora & 1 & 4,55 \\
Merendeira & 1 & 4,55 \\
\hline
\end{tabular}




\begin{tabular}{lcc}
\hline Diarista & 2 & 9,09 \\
Funcionária Pública & 1 & 4,55 \\
Manicure & 2 & 9,09 \\
Biomédico & 1 & 4,55 \\
Serviços Gerais & 1 & 4,55 \\
\hline Total & $\mathbf{2 2}$ & $\cong \mathbf{1 0 0}$ \\
\hline
\end{tabular}

A respeito da faixa etária das crianças, foi identificado que 14 (63,64\%) estavam entre dois e 42 meses de idade. O tempo de internação variou entre um e 20 dias, com vinte (90,91\%), conforme a tabela 3.

Tabela 3 - Faixa etária e tempo de internação das crianças no hospital. Manaus, AM, Brasil, 2016

\begin{tabular}{lcc}
\hline Variável & $\mathbf{n}$ & $\%$ \\
\hline Faixa Etária & 14 & 63,63 \\
\hline 2 a 42 meses & 3 & 13,63 \\
43 a 83 meses & 3 & 13,63 \\
84 a 124 meses & 1 & 4,54 \\
125 a 165 meses & 1 & 4,54 \\
166 a 206 meses & 22 & $\cong 100$ \\
Total & & \\
\hline Dias de internação & 20 & 90,91 \\
\hline 1 a 20 dias & 1 & 4,55 \\
21 a 41 dias & 1 & 4,55 \\
\hline 2 a 62 dias & 22 & $\cong 100$ \\
\hline Total
\end{tabular}

Quanto ao diagnóstico clínico dos pacientes, os dados evidenciam que o motivo da internação em clínica cirúrgica, seguindo a ordem de ocorrência, foi de imperfuração anal, megacólon e hérnia inguinal, correspondente a 13,64\% dos casos; teratoma e cálculo renal foram encontrados em 9,09\% dos diagnósticos e outros casos como: estenose retal; criptorquidia; hérnia escrotal; artresia esofágica; estenose esofágica e gástrica; megacólon anal e Congênito e teratoma anal; cisto umbilical; hidrocele e hérnia epigástrica (cada um com 4,55\%, respectivamente).

Os resultados foram apresentados de modo sistematizado buscando identificar a percepção dos pais quanto ao brincar como uma dimensão do cuidar. Para melhor compreensão da pesquisa, após a fase de organização, agrupamento e categorização, emergiram três categorias temáticas a partir da coleta de dados: "O significado da brincadeira e do brincar na ótica dos familiares", "A importância do brinquedo durante a prática do brincar para a criança hospitalizada" e "O cuidar brincando".

\section{O significado da brincadeira e brincar na ótica dos familiares}

Na perspectiva dos acompanhantes, o brincar altera o humor da criança que se desestrutura devido à internação. Com o brincar, a mesma se sente mais alegre, passa a ter mais liberdade no ambiente hospitalar contribuindo e acelerando o seu processo de recuperação.

[...] vem gente brincar, ele vai esquecendo [...] só de ele brincar ela já esqueceu que tá aqui no hospital. (Mayoruna - 24 anos) 
[...] a criança ela tendo um espacinho [...] um lugarzinho pra ela brincar, ela se recupera bem rápido [...]. (Katukina - 34 anos)

O desenvolvimento da brincadeira, durante o tratamento, promove alegria e distração para a criança. O brincar faz com que a mesma esqueça, por um momento, o local onde se encontra e minimiza o possível estresse causado pela doença e pela hospitalização possibilitando a aceitação do tratamento no ambiente hospitalar.

Segundo os acompanhantes, as crianças gostam de brincar e, com o brinquedo, podem construir um mundo de fantasias, além de momentos recreativos proporcionadores de alegria e uma sensação de bem-estar favorecendo o alívio da dor e a melhora da condição de saúde.

[...] a criança fica mais alegre e a gente vê que ela para de pensar um pouco na doença. (Sateré-Mawé -34 anos)

\section{[...] brincando, vai esquecer as coisas que ela passa, coisas ruins. (Kulina - 28 anos)}

Nesse sentido, a percepção dos acompanhantes indica que o uso do brinquedo proporciona mudança no comportamento da criança deixando-a mais tranquila e segura para a realização do cuidado no ambiente hospitalar.

\section{A importância do brinquedo durante a prática do brincar para a criança hospitalizada}

O brinquedo, para a criança hospitalizada, na percepção dos acompanhantes, ajuda na recuperação durante o tratamento e é visto, também, como um auxílio para suprimir o medo dos procedimentos dolorosos realizados causando efeito tranquilizador e consolidando a necessidade de atividades recreativas como ferramenta importante no processo de recuperação.

Os discursos dos acompanhantes revelam que o brincar se configura em uma fuga da realidade e lembrança do momento feliz da infância. Ao serem interrogados sobre os brinquedos que as crianças conheciam, as respostas foram: bola, boneca, casinha, corda, avião, peteca, pipa, elástico e carrinho, assim como brincadeiras de rua, amarelinha, pega-pega, esconde-esconde, manja queimada, roda, pata-cega, adoleta e futebol.

[...] o brinquedo acalma uma criança [...] eu acho que, a partir do momento que ela tem um brinquedo, alguma brincadeira [...], ela vai ficar bem [...] deve ajudar bastante na recuperação da criança [...]. (Atroari - 21 anos)

[...] acho que a criança tem medo de agulha [...] e, com o brinquedo, ele ia esquecer o medo de agulha, da dor [...]. (Mayoruna - 24 anos)

\section{O cuidar brincando}

Os acompanhantes sugerem que, na unidade hospitalar, deve haver um ambiente onde as crianças possam vivenciar momentos recreativos suprindo as necessidades de brincar por meio da brinquedoteca e do uso de brinquedos lúdicos coordenado por pessoas capazes de estimular a participação da criança nas atividades.

Acho que devia ter uma brinquedoteca com brinquedos, com alguém para ficar orientando [...]. (Matis -34 anos)

Acho que deveria ter aqui uma sala cheia de brinquedos para as crianças brincarem [...]. (Ticuna - 28 anos)

O uso de brincadeiras com músicas, contos e estórias nos leitos, com a utilização de brinquedos ou simplesmente a atuação de grupo de palhaços, proporcionando um momento de descontração, também foi sugerido durante a pesquisa.

[...] devem trazer o canto, a alegria, é brincar, dialogar. Além da música, devem trazer brinquedos [...] a palhaçada de um palhaço [...]. (Baniwa - 20 anos) 
Eu acho que deviam contar histórias, literaturas, brincadeira de palhaços [...]. (Jarawara - 25 anos)

Observou-se, também, que, embora os pais aprovem o brincar no hospital e reconheçam seus benefícios, eles também se mostraram preocupados quanto à forma de brincar, reconheceram que não deve haver muito barulho ou desordem no momento da brincadeira, pois as crianças precisam estar protegidas de qualquer intercorrência, prezando pelo bem-estar físico e psíquico de forma a conciliar a brincadeira com o seu estado de saúde.

Não fazendo tanta arruaça, tanto barulho [...] contar uma história [...] não fazer barulho, essas coisas [...] andar, conversar, um sorriso, fazer a criança sorrir, contar uma piada, fazer ela dar uma gargalhada [...]. (Apurinã - 22 anos)

[...] esse brincar deve ter um certo cuidado, não pode ser qualquer tipo de diversão porque as crianças aqui estão em tratamento, então, não sabemos a que ponto podemos ir e o que pode ajudar ou mesmo sem querer prejudicar [...]. (Hixkaryana - 50 anos)

Os acompanhantes apontaram alguns questionamentos em relação à utilização dos brinquedos no ambiente pediátrico de internação ao relatar que ainda se sentem receosos quanto ao método utilizado para a diversão da criança por não saber, ao certo, o que podem ou não fazer devido ao fato de que, na maioria das vezes, as crianças se encontram com o acesso para o soro ou bombas de infusão.

\section{DISCUSSÃO}

A brincadeira e o brincar no contexto hospitalar, na percepção dos pais, são recursos imprescindíveis durante a hospitalização e o tratamento da criança para aliviar o medo. O brincar favorece a manutenção e experimentos dos hábitos diários do infante reduzindo a ociosidade e desenvolvendo o cuidar, em sua integralidade, no ambiente pediátrico ${ }^{(15)}$.

Nesse contexto, a visão dos pais quanto às necessidades da criança hospitalizada é de que a brincadeira é indispensável em sua rotina diária e a utilização do brinquedo terapêutico também propicia o momento ideal para explicar, à criança, a importância do tratamento e dos cuidados que ela está recebendo da equipe de saúde(2).

Assim, o brincar no hospital proporciona, à criança, oportunidades de vivenciar esse novo momento em sua vida, de estar doente e hospitalizada, de forma menos estressante, reduzindo os efeitos negativos da ruptura com seu convívio social, com melhor adaptação durante a internação, o que facilita, ao infante, mais a receptividade, o acolhimento e meios para enfrentar as situações advindas do efeito da hospitalização( ${ }^{(8)}$.

Os relatos apresentados ressaltam que o brinquedo, durante os momentos destinados às brincadeiras realizadas com a criança hospitalizada, produz distração e bem-estar permitindo o desanuviamento do ambiente pesado de dor e sofrimento. Portanto, a prática do brincar proporciona meios para o infante se expressar exteriorizando suas vivências mais marcantes durante o tratamento e suas rotinas ${ }^{(16)}$.

Assim, o brinquedo trabalha, na criança, conceitos como a socialização, a ponderação entre perdas e ganhos, os trabalhos em cooperação, a recreação e a alternância de momentos felizes e tristes que fazem parte do dia a dia de cada ser humano ${ }^{(17)}$.

Em outros estudos, os acompanhantes relatam que o uso do brinquedo terapêutico faz com que ocorra a exteriorização da doença tornando a criança mais segura quanto ao tratamento ${ }^{(16)}$.

Outro ponto de interesse, evidenciado na pesquisa, é a necessidade que os acompanhantes sentem de ter um profissional com competências e habilidades para realizar o brincar garantindo o sucesso dessa terapia. Nesse sentido, o profissional que se propuser a trabalhar como "brinquedista", no ambiente da brinquedoteca, deve possuir formação voltada para o lúdico devido à necessidade de ter melhor entendimento da educação infantil, pois a criança está em formação do seu processo psicossocial e se espelha no adulto ${ }^{(7)}$. 
Para os acompanhantes, há a necessidade de profissional que trabalhe com o lúdico ou até mesmo palhaços que realizem, junto à criança, brincadeiras, redirecionando seu pensamento ao mundo de sonho, metamorfoseando o momento vivido com sentimentos positivos e benéficos que propiciem mudança de comportamento, deixando a criança hospitalizada mais relaxada, atenta e sorridente ${ }^{(18)}$.

Ressalta-se que os dados das categorias concordam com outros estudos realizados, evidenciadores da importância da atividade do brincar para a criança, onde o trabalho desses profissionais habilitados em unidades hospitalares ameniza o tempo de espera, ajuda no desconforto da dor e aumenta o nível da disposição física da criança, expresso por meio do sorriso no rosto com melhora da autoestima, diminuindo o sentimento da angústia sofrida no processo de tratamento por meio de motivação lúdica ${ }^{(5)}$.

Os depoimentos apresentados na categoria "O cuidar brincando" são compatíveis com outro estudo $^{(19)}$ realizado com profissionais de saúde, que demonstraram desconhecer as peculiaridades da criança em relação à necessidade de brincar, mesmo hospitalizadas, verbalizando que o brincar deve ter limitações. Portanto, o desafio dos profissionais de Enfermagem é a assimilação do brincar com a prática do cuidado, sendo uma dificuldade recorrente, pois o brincar não é um cuidado de Enfermagem previamente prescrito, ele é uma atividade que deve ser trabalhada pelos profissionais, de forma própria e individual, pois cada criança reage de maneira diferente ao mesmo estressor ${ }^{(19)}$.

Os achados desta categoria corroboraram o estudo que mostrou a utilização do brinquedo como um mecanismo de proteção capaz de divertir e encorajar proporcionando calma e aceitação do cuidado. Nesse contexto, considera-se a presença do profissional importante como mediador das brincadeiras, com ações atrativas e estimulantes, inserindo o pequeno paciente em uma situação ativa e reativa, protagonista do cuidado e não na posição de espectador ${ }^{(20)}$.

Diante disso, a experiência hospitalar, uma vez que se apresenta como traumática, provoca sentimentos de isolamento e solidão como forma de defesa, o que poderia ser amenizado se houvesse uma maior interação da equipe de Enfermagem com a criança ${ }^{(21)}$.

Os pais possuem conhecimento empírico sobre a condição de saúde da criança. Entretanto, buscam informações sobre o cuidar, pautadas na integralidade, com o intuito de transcender suas incertezas e auxiliar no enfrentamento futuro das complicações da doença ${ }^{(22)}$.

A limitação do estudo identificada está pautada no desafio da realização do uso do brinquedo ou brincadeira pelos pais por eles receberem, dos profissionais de Enfermagem, informações subjetivas acerca do manejo da criança no desdobramento dos diversos momentos da hospitalização.

\section{CONCLUSÃO}

O estudo traz a percepção dos pais em relação ao cuidado por meio do brincar, na unidade pediátrica, onde se registrou a necessidade dos pais em ter conhecimento sobre a importância desta prática no processo assistencial oportunizando à criança doente possibilidades de transformação no aspecto imprevisível e doloroso da internação infantil em algo prazeroso de modo a expor seus sentimentos e vivenciar, de forma minimizada, o sofrimento, o trauma e a hospitalização.

O brincar, por ser uma necessidade natural da criança, deve ser estimulado. Entretanto, os familiares/ responsáveis legais sentem-se inseguros em realizar as brincadeiras por desconhecer os limites da doença e seu tratamento referindo-se à necessidade de um profissional que os oriente na execução das brincadeiras. Desta forma, o cuidar, por meio do brincar, contribui para que a unidade pediátrica não seja apenas um espaço de tratamento, mas um ambiente promotor de atividades lúdicas para as crianças e acompanhantes expressando, assim, a importância da participação da equipe que presta cuidado com o protagonismo do brincar.

Conhecer a percepção dos pais sobre o brincar em ambiente hospitalar apresenta uma realidade que deve ser reconstruída pelos profissionais que estão inseridos neste contexto humanizando o cuidado, que deve ser pautado não apenas no tecnicismo, mas, embasado na coparticipação da família, da criança e do profissional, oportunizando o cuidar brincando de forma dinâmica e menos traumática. 


\section{- REFERÊNCIAS}

1. de Nóbrega RD, Collet N, Gomes IP, de Holanda ER, de Araújo YB. Criança em idade escolar hospitalizada: significado da condição crônica. Texto contexto - enferm. [Internet] 2010;19(3) [acesso em 09 jul 2016]. Disponível: http:// dx.doi.org/10.1590/S0104-07072010000300003.

2. Dias A, Brum T, Zottele C, de Freitas HMB, Colomé JS, Backes DS. Pais com filhos internados em unidade pediátrica: contribuições da equipe do PET-Saúde para o cuidado. Disciplinarum Scientia. [Internet] 2014;15(2) [acesso em 09 jul 2016]. Disponível: http://www.periodicos.unifra.br/index.php/disciplinarumS/article/view/1080.

3. Dahdah DF,Carvalho AMP, Delsim JC, Gomes BR, de Miguel VS. Grupo de familiares acompanhantes de pacientes hospitalizados: estratégia de intervenção da Terapia Ocupacional em um hospital geral. Cad. Ter. Ocup. UFSCar. [Internet] 2013;21(2) [acesso em09 jul 2016]. Disponível: http://doi.editoracubo.com.br/10.4322/cto.2013.041.

4. Gomes GC, Nicola GDO, de Souza NZ, Chagas MCS, Farias RFD, Xavier DM. Percepções da família acerca das dificuldades de adaptação da criança à hospitalização: subsídios para a enfermagem. Cogitare Enferm. [Internet] 2013;18(4) [acesso em 15 de ago 2016]. Disponível: http://dx.doi.org/10.5380/ce.v18i4.34935.

5. Cunha GL,da Silva LF. Lúdico como recurso para o cuidado de enfermagem pediátrica na punção venosa. Rev. Rene. [Internet] 2012;13(5) [acesso em 09 de jul 2016]. Disponível: http://www.revistarene.ufc.br/revista/index.php/revista/ article/view/49.

6. Brasil. Lei n. 11.104, de 21 de março de 2005. Dispõe sobre a obrigatoriedade de instalação de brinquedotecas nas unidades de saúde que ofereçam atendimento pediátrico em regime de internação. Diário Oficial da União, Brasília, 22 mar. 2005. Seção 1.

7. de Nez E, Moreira JAN. Reflexões sobre a utilização da brinquedoteca na educação infantil: um estudo de caso no norte de Mato Grosso. Rev. Fac. Educ. [Internet] 2013;19(1) [acesso em 16 jul 2016].Disponível: http://www2.unemat. br/revistafaed/content/vol/vol_19/artigo_19/129_145.pdf.

8. Sousa LC, Vitta A, de Lima JM, Vitta FCF. O brincar no contexto hospitalar na visão dos acompanhantes de crianças internadas. Journal of Human Growth and Development. [Internet] 2015;25(1) [acesso em 16 jul 2016]. Disponível: http://dx.doi.org/10.7322/JHGD.96766.

9. Montrone AVG, Rani R, Takaesu RK, Arantes Cl, Fabbro MRC. Percepções e práticas de cuidadoras comunitárias no cuidado de crianças menores de três anos. Trab. educ. saúde. [Internet] 2013;11(3) [acesso em 13 jul 2016]. Disponível: http://dx.doi.org/10.1590/S1981-77462013000300011.

10. da Silva LF,Cabral IE. O resgate do prazer de brincar da criança com câncer no espaço hospitalar. Rev. Bras. Enferm. [Internet] 2015;68(3) [acesso em13 jul 2016]. Disponível: http://dx.doi.org/10.1590/0034-7167.2015680303i.

11. Sposito AMP, Sparapani VC, Pfeifer LI, de Lima RAG, Nascimento LC. Playful strategies for data collection with child cancer patients: an integrative review. Rev. Gaúcha Enferm. [Internet] 2013;34(3) [acesso em 13 jul 2016]. Disponível: http://dx.doi.org/10.1590/S1983-14472013000300024.

12. Hostert PCCP, Enumo SRF, Loss ABM. Brincar e problemas de comportamento de crianças com câncer de classes hospitalares. Psicol. teor. prat. [Internet] 2014;16(1) [acesso em 21 jul 2016]. Disponível: http://dx.doi.org/10.15348/19806906/psicologia.v16n1p127-140.

13. Minayo MCS. O desafio do conhecimento: Pesquisa Qualitativa em Saúde. 14ํㅡㄹ ed. São Paulo: Hucitec-Abrasco; 2014.

14. Conselho Federal de Enfermagem. Resolução n. 295, de 24 de outubro de 2004. Dispõe sobre a utilização da técnica do brinquedo terapêutico pelo enfermeiro na assistência à criança hospitalizada. Rio de janeiro: COFEN; 2004. 
15. Lima MBS, Oliveira LSM, Magalhães CMC, da Silva ML. Brinquedoteca hospitalar: a visão dos acompanhantes de crianças. Psicol. teor. prat. [Internet] 2015;17(1) [acesso em 22 jul 2016]. Disponível: http://pepsic.bvsalud.org/scielo. php?script=sci_arttext\&pid=S1516-36872015000100009.

16. Lima CA, de Figueiredo CR, do Prado PF, Leite MTS. Brinquedo terapêutico no cuidado integral à criança hospitalizada: significados para o familiar acompanhante. Revista Unimontes Científica. [Internet] 2015;17(2) [acesso em 22 jul 2016]. Disponível: http://www.ruc.unimontes.br/index.php/unicientifica/article/view/401.

17. Malaquias TSM, Baena JA, Campos APS, Moreira SRK, Bladissera VDA, Higarashi IH. O uso do brinquedo durante a hospitalização infantil: saberes e práticas da equipe de enfermagem. Cienc. Cuid. Saude. [Internet] 2014;13(1) [acesso em 22 jul 2016]. Disponível: http://www.periodicos.uem.br/ojs/index.php/CiencCuidSaude/article/view/21802.

18. Alcântara PL,Wogel AZ, Rossi MIL, Neves IR, Sabates AL, Puggina AC. Efeito da interação com palhaços nos sinais vitais e na comunicação não verbal de crianças hospitalizadas.Rev. Paul. Pediatr. [Internet] 2016;34(4) [acesso em 29 mai 2016]. Disponível: https://doi.org/10.1016/j.rpped.2016.02.001.

19. Marques EP, Garcia TMB, Anders JC, Luz JH, Rocha PK, de Souza S. Lúdico no cuidado à criança e ao adolescente com câncer: perspectivas da equipe de enfermagem. Esc. Anna Nery. [Internet] 2016;20(3) [acesso em 29 mai 2016]. Disponível: http://dx.doi.org/10.5935/1414-8145.20160073.

20. Sommerhalder A. Alves FD. Jogo e a educação da infância: muito prazer em aprender. 1ํㅡㄹ ed. Curitiba: CRV; 2011.

21. Dias JJ, Silva APC, Freire RLS, Andrade ASA. A experiência de crianças com câncer no processo de hospitalização e no brincar.Rev. Min. Enferm. [Internet] 2013;17(3) [acesso em 26 ago 2016]. Disponível: http://www.dx.doi. org/10.5935/1415-2762.20130045.

22. de Melo EMOP, Ferreira PL, de Lima RAG, de Mello DF. Envolvimento dos pais nos cuidados de saúde de crianças hospitalizadas. Revista Latino-Am. Enfermagem. [Internet] 2014;22(3) [acesso em 27 mar 2018]. Disponível: http:// dx.doi.org/10.1590/0104-1169.3308.2434. 